\title{
Comparison of Different MPPT Algorithms with a Proposed One Using a Power Estimator for Grid Connected PV Systems
}

\author{
Manel Hlaili and Hfaiedh Mechergui \\ Electrical Engineering, High National School of Engineers of Tunis, University of Tunis, 1008 Tunis, Tunisia \\ Correspondence should be addressed to Manel Hlaili; hlaili_manel@yahoo.fr
}

Received 4 April 2016; Accepted 17 May 2016

Academic Editor: Vishal Mehta

Copyright ( 2016 M. Hlaili and H. Mechergui. This is an open access article distributed under the Creative Commons Attribution License, which permits unrestricted use, distribution, and reproduction in any medium, provided the original work is properly cited.

Photovoltaic (PV) energy is one of the most important energy sources since it is clean and inexhaustible. It is important to operate PV energy conversion systems in the maximum power point (MPP) to maximize the output energy of PV arrays. An MPPT control is necessary to extract maximum power from the PV arrays. In recent years, a large number of techniques have been proposed for tracking the maximum power point. This paper presents a comparison of different MPPT methods and proposes one which used a power estimator and also analyses their suitability for systems which experience a wide range of operating conditions. The classic analysed methods, the incremental conductance (IncCond), perturbation and observation (P\&O), ripple correlation (RC) algorithms, are suitable and practical. Simulation results of a single phase NPC grid connected PV system operating with the aforementioned methods are presented to confirm effectiveness of the scheme and algorithms. Simulation results verify the correct operation of the different MPPT and the proposed algorithm.

\section{Introduction}

Renewable sources of energy are a hot topic acquiring a growing importance in the world due to its consumption and exhaustion of fossil fuel. The photovoltaic (PV) power system is becoming increasingly important as the most available renewable source of energy since it is clean with little maintenance and without any noise.

Nevertheless, PV systems have problems, such as the conversion with low radiation (in general less than $17 \%$ ), as well as the nonlinear characteristic that depends on irradiation and temperature in its operation which change the amount of electric power generated [1]. Figures 1 and 2 show the characteristics $P-V$ and $I-V$ for different irradiation and temperature.

Since a PV array is an expensive system to build, it is necessary to exploit all of the available output power. Multilevel converters are particularly interesting for high power applications.

The location of the maximum power point can be determined using different algorithms. Maximum Power Point Tracking (MPPT) techniques are used to maintain the PV array's operating point at its maximum power point (MPP) and extract the maximum power available in PV arrays.

Different MPPT techniques have been proposed in the literature such as the perturbation and observation ( $\mathrm{P} \& \mathrm{O})$ technique [2], the incremental conductance (IncCond) technique [3], ripple correlation technique [4], short circuit current (SCC) technique [5], and open circuit voltage (OCV) technique [5].

These techniques vary in complexity, cost, speed of convergence, sensors required, hardware implementation, and effectiveness.

Due to the various MPPT methods, different research in PV systems has presented a comparative analysis of MPPT techniques. Indeed, some papers present comparative study among only few methods and others present a comparison of several MPPT methods, based on simulations, under the energy production point of view. The MPPT techniques are evaluated considering different irradiation and tempreature variation and calculation of the energy supplied by the complete PV array.

In this paper, the attention will be concentrated on PSIM simulation comparisons between some of these techniques 


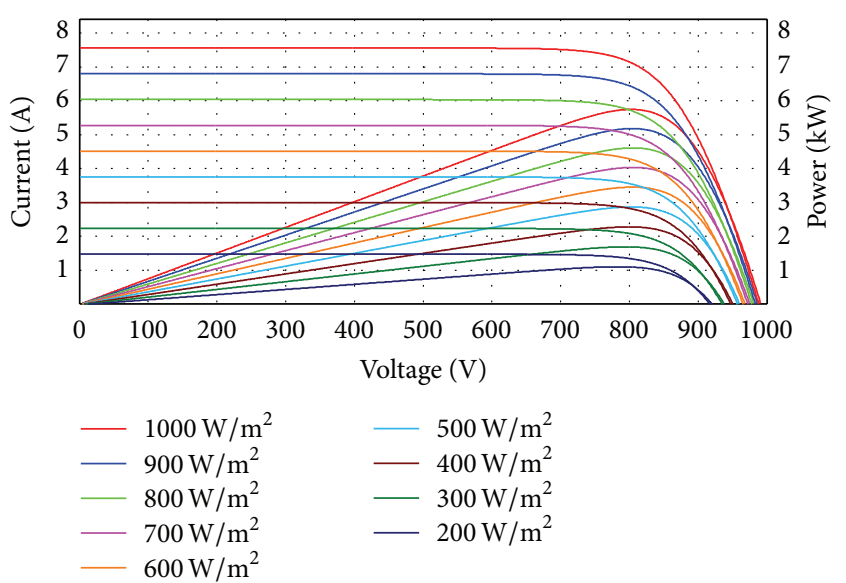

Figure $1: I-V$ and $P-V$ curve with different irradiation.

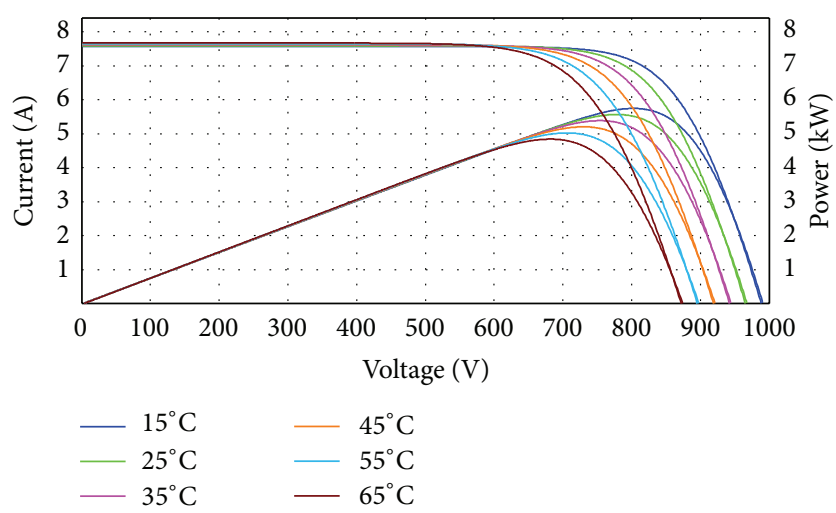

Figure 2: $I-V$ and $P-V$ curve with temperature variation.

and a proposed method will be discussed using the short circuit current and the open circuit voltage. Consequently, the purpose of this work is to compare several widely adopted MPPT algorithms between the different MPPT techniques in order to understand which technique has the best performance with the proposed method as well as injecting the high quality sinusoidal current to the grid.

In the simulations, the MPPT techniques have been implemented strictly following the description indicated in the references excluding the proposed algorithm. In particular, we will focus our attention on a grid connected photovoltaic system constructed by connecting a single phase neutral point clamped inverter (SP-NPCI) with an inductor as an output filter, using different embedded MPPT algorithms.

\section{Operating Principle}

The SP-NPCI output current is controlled in order to follow a sinusoidal reference waveform, synchronized, and in phase with the grid voltage.

Figure 3 shows the scheme of the proposed system with its control.

Using a phase-locked loop (PLL) algorithm, we can extract a unitary signal in phase with the grid voltage. The amplitude of the reference current $I_{\text {ref }}$ is generated by the sum of the DC-link voltage regulator and the output of the MPPT. The MPPT algorithm varies $I_{\mathrm{MPPT}}$ according to the environmental conditions in order to keep the operating point of the PV system close to the maximum power point.

The switches $T_{1}$ and $T_{3}$, as well as $T_{2}$ and $T_{4}$, are switched complementarily. The control of this inverter can be done using a PWM technique. To implement the PWM, two superposed triangular carriers are used. Each carrier is connected to one of the two groups of switches controlled complementarily. The positive part of the carrier fixes the switching state of $T_{1}$ and $T_{3}$ whereas the negative part controls $T_{2}$ and $T_{4}$.

\section{MPPT Algorithms}

The maximum power supplied by the photovoltaic panels is not always stable and fixed in the same operating point; it varies with the weather conditions, such as solar irradiation, shadow, and temperature. To extract the maximum power, it is necessary to implement an MPPT algorithm that dynamically adjusts the extraction of the power. Convergence speed is one of the most important features among all different MPPT algorithms. Any improvement in the rise time of MPPT improves the reliability of the system and increases the power extraction and efficiency of the whole system.

3.1. Perturbation and Observation (PঊO). Perturb and observe algorithm is simple and does not require previous knowledge of the PV generator characteristics or the measurement of solar intensity and cell temperature and is easy to implement with analogue and digital circuits. It perturbs the operating point of the system causing the PV array terminal voltage to fluctuate around the MPP voltage even if the solar irradiance and the cell temperature are constants [6].

Moreover, it is the most widely used and workhorse MPPT algorithm because of its balance between performance and simplicity. However, it suffers from the lack of speed and adaptability which is necessary for tracking the fast transients under varying environmental conditions [7]. It is simple and straightforward technique but degraded performance is achieved due to the trade-off between accuracy and speed upon selecting the step size [8]. Figure 4 shows the P\&O algorithm diagram.

3.2. Incremental Conductance (IncCond). The incremental conductance method is based on the principle that the slope of the PV array power curve is zero at the MPP, so that $\Delta P / \Delta V=0$, with $P=V I$.

Considering that

$$
\begin{array}{ll}
\frac{\Delta I}{\Delta V}=-\frac{I}{V} & \text { if } P=\mathrm{MPP}, \\
\frac{\Delta I}{\Delta V}>-\frac{I}{V} & \text { if } P<\mathrm{MPP}, \\
\frac{\Delta I}{\Delta V}<-\frac{I}{V} & \text { if } P>\mathrm{MPP},
\end{array}
$$




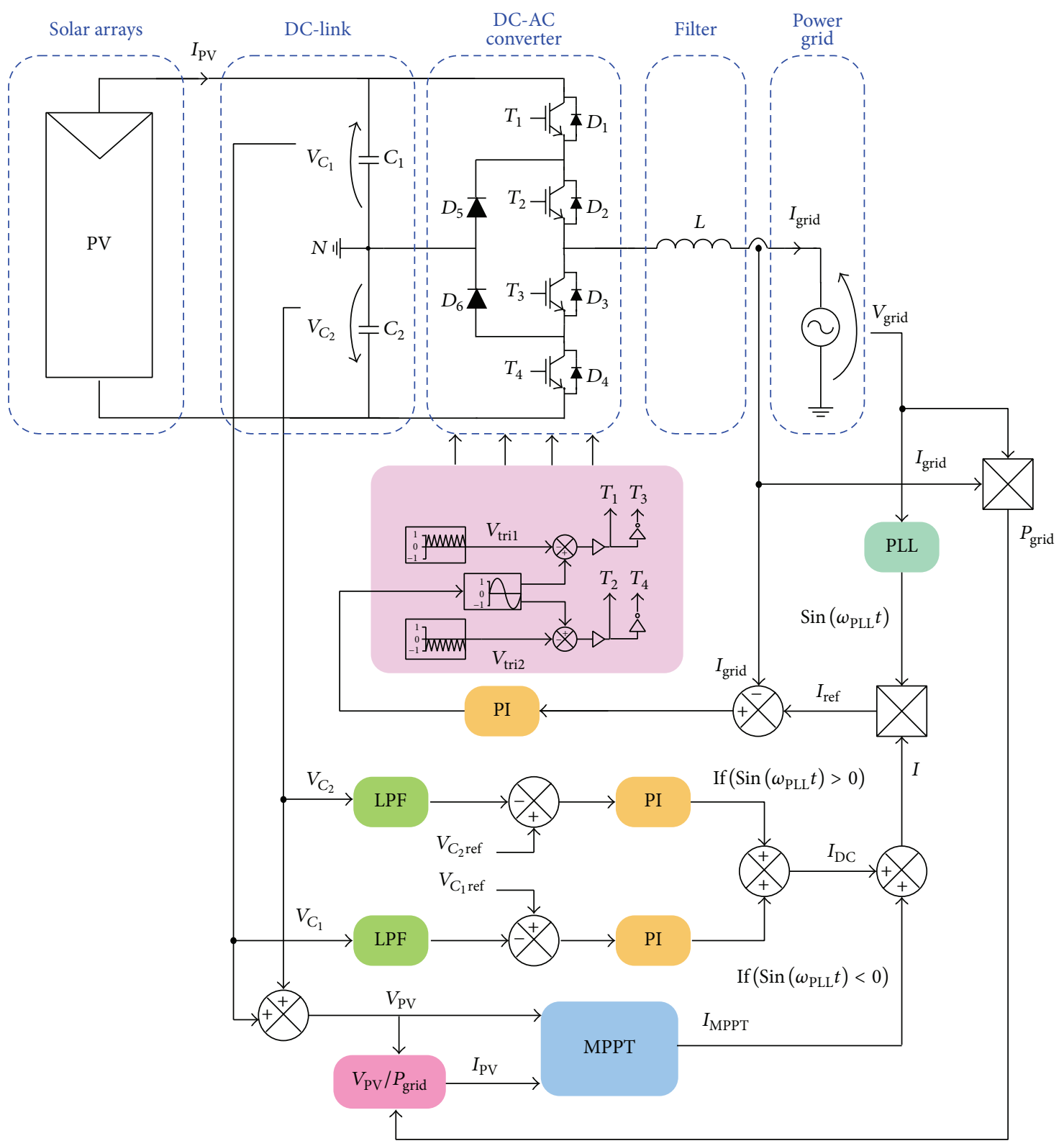

FIGURE 3: Scheme of the control system including the MPPT.

the MPP can be tracked by comparing the instantaneous conductance $I / V$ with the incremental conductance $\Delta I / \Delta V$.

The algorithm increments or decrements the reference until the condition $\Delta I / \Delta V=-I / V$ is achieved. Once the maximum power is reached, the operation of the PV array is maintained at this point. It is an effective algorithm and requires high sampling rates and fast calculations of the power slope [9]. It offers different advantages which are good tracking efficiency and automatic adjustment of the module operating voltage with no oscillations. Also, the response is improved and the control for the extracted power is optimized [10]. The implementation of this algorithm in the control unit is difficult and expensive, but with recent developments in microcontrollers it became more cost effective [11]. It lends itself well to DSP control, which can easily keep track of previous values of voltage and current [12]. Figure 5 shows the IncCond algorithm.

3.3. Ripple Correlation. If the grid current $I_{\text {grid }}(t)$ is in phase with the grid voltage $V_{\text {grid }}(t)$, the instantaneous value of power injected into the grid is

$$
P_{\text {grid }}(t)=V_{\text {grid }} I_{\text {grid }}(1+\cos 2 \omega t) .
$$

From (2), the instantaneous power $P_{\text {grid }}(t)$ pulsates at a frequency twice that of the grid ( $2 \omega$ is produced), making the ripple included in PV voltage, current, and power. For that, the behavior of the PV voltage ripple $\widetilde{V}_{\mathrm{PV}}$ as well as PV power ripple $\widetilde{P}_{\mathrm{PV}}$ is used to find out the direction of the MPPT of the SP-NPCI. 


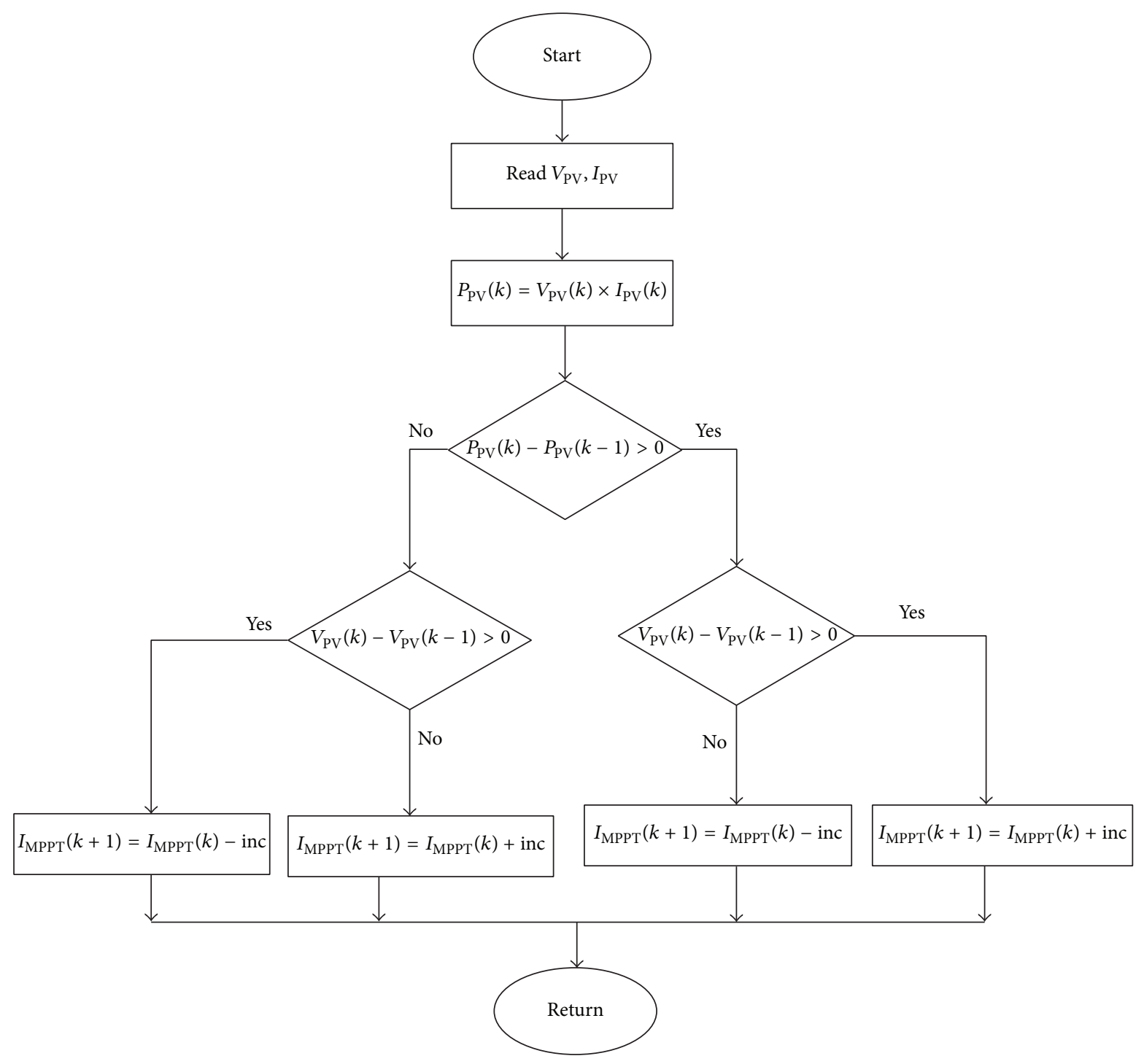

Figure 4: Flowchart of perturbation and observation.

The ripple correlation control uses the average function to find out the average term of the instantaneous PV power $\bar{P}_{\mathrm{PV}}$ and voltage $\bar{V}_{\mathrm{PV}} \cdot \widetilde{P}_{\mathrm{PV}}$ and $\widetilde{V}_{\mathrm{PV}}$ can be calculated from

$$
\begin{aligned}
& \widetilde{P}_{\mathrm{PV}}=P_{\mathrm{PV}}-\bar{P}_{\mathrm{PV}}, \\
& \widetilde{V}_{\mathrm{PV}}=V_{\mathrm{PV}}-\bar{V}_{\mathrm{PV}} .
\end{aligned}
$$

The average value of $\widetilde{V}_{\mathrm{PV}} \times \widetilde{P}_{\mathrm{PV}}$ function is the output of $\partial P$ :

$$
\partial P=\overline{\widetilde{P} \cdot \widetilde{V}} .
$$

The sign of $\partial P$ is an indication of the region where the PV system is working:

(i) $\partial P>0$ : the operating point is on the left side of the MPP on the $(P-V)$ characteristic; then, the sign function is +1 . (ii) $\partial P<0$ : the operating point is on the right side of the MPP on the $(P-V)$ characteristic; then, the sign function is -1 .

The knowledge of the instantaneous operating point region makes it possible to change the output reference current in order to approach the maximum power operating point. This method presents very fast dynamics converging asymptotically to the MPP, and it achieves convergent speeds at a rate similar to the switching converter frequency. Figure 6 shows the ripple correlation MPPT algorithm.

3.4. Proposed MPPT. The proposed MPPT is a combination of the open circuit voltage and the short circuit current methods with a variable step size (VSSOCV) in the gain parameters which is multiplied by the open circuit voltage to have the maximum power which can be extracted from the PV panels. In addition to that, we proposed a power 


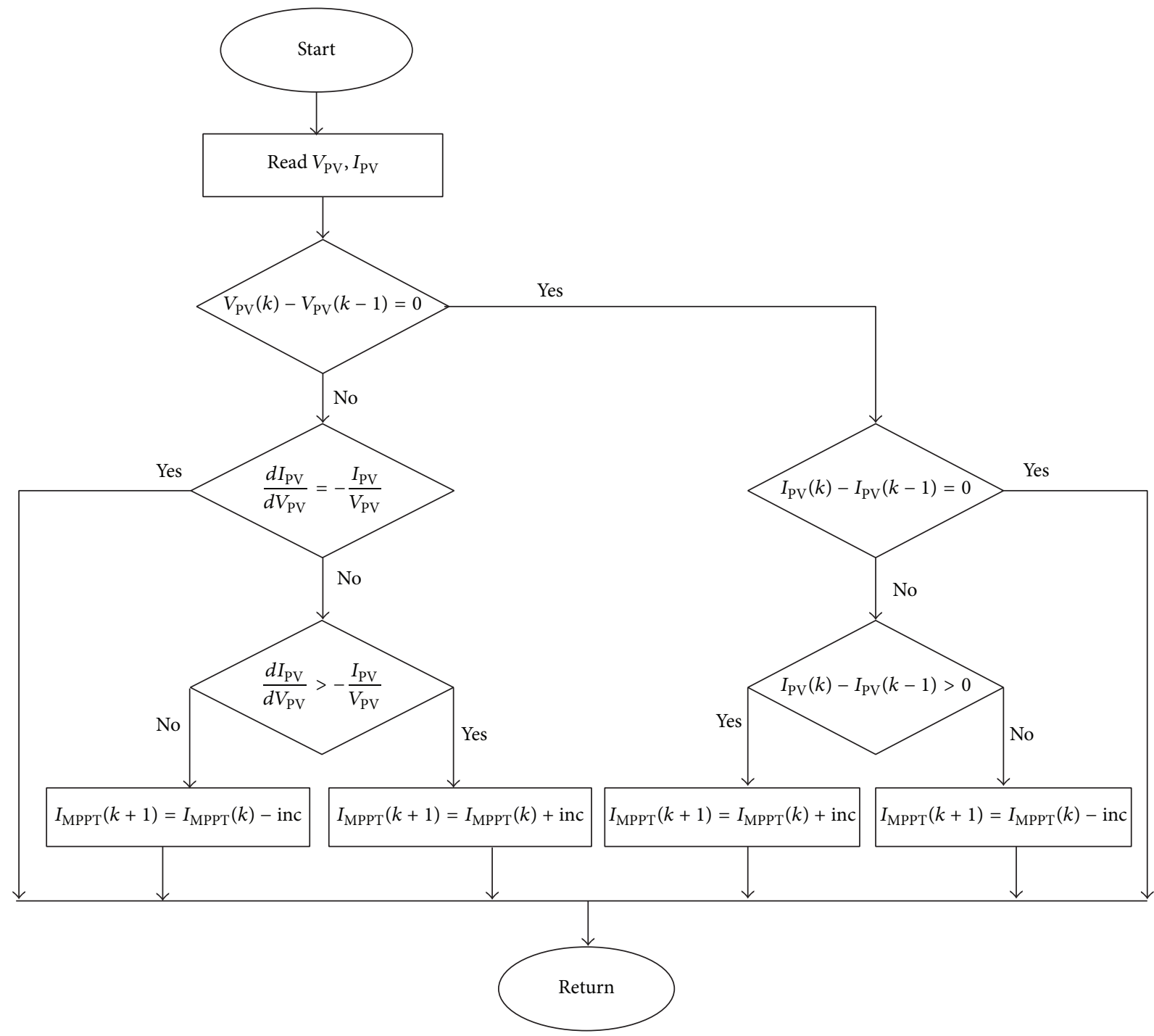

Figure 5: Flowchart of the incremental conductance algorithm.

estimator, to measure the power from the DC side of the PV system.

In case the grid current is in phase with the grid voltage, the instantaneous PV power, upon neglecting power losses in NPC inverter, is given by

$$
P_{\mathrm{PV}}=P_{L}+P_{C}+P_{\text {grid }}(t) \text {. }
$$

We can estimate the instantaneous power extracted from the panel using the current and the voltage injected into the grid.

Figure 7 shows that the OCV is proportional to the variation of temperature which is given by

$$
V_{\mathrm{OC}}=-k_{1} * T+k \text {. }
$$

The maximum voltage extracted from the PV system is equal to

$$
V_{\mathrm{MPP}}=k_{2} * V_{\mathrm{OC}}
$$

The factor $k_{2}$ is always less than unity. It looks very simple but determining the best value of it is very difficult. It varies from 0.73 to 0.8 [5].

The SCC of the PV panel depends on the irradiation. This relationship can be described by

$$
I_{\mathrm{SC}}=k_{3} * E .
$$

The constant $k_{3}$ can be determined from the PV characteristic.

Figure 8 shows that the SCC is proportional to the variation of the irradiation.

However, the optimum operating current for maximum output power is proportional to the short circuit current under various irradiation [5]:

$$
I_{\mathrm{MPP}}=k_{4} * I_{\mathrm{SC}},
$$

where $k_{4}$ is a proportional constant which varies from 0.8 to 0.9 . This control algorithm requires the measurement of the SCC. 


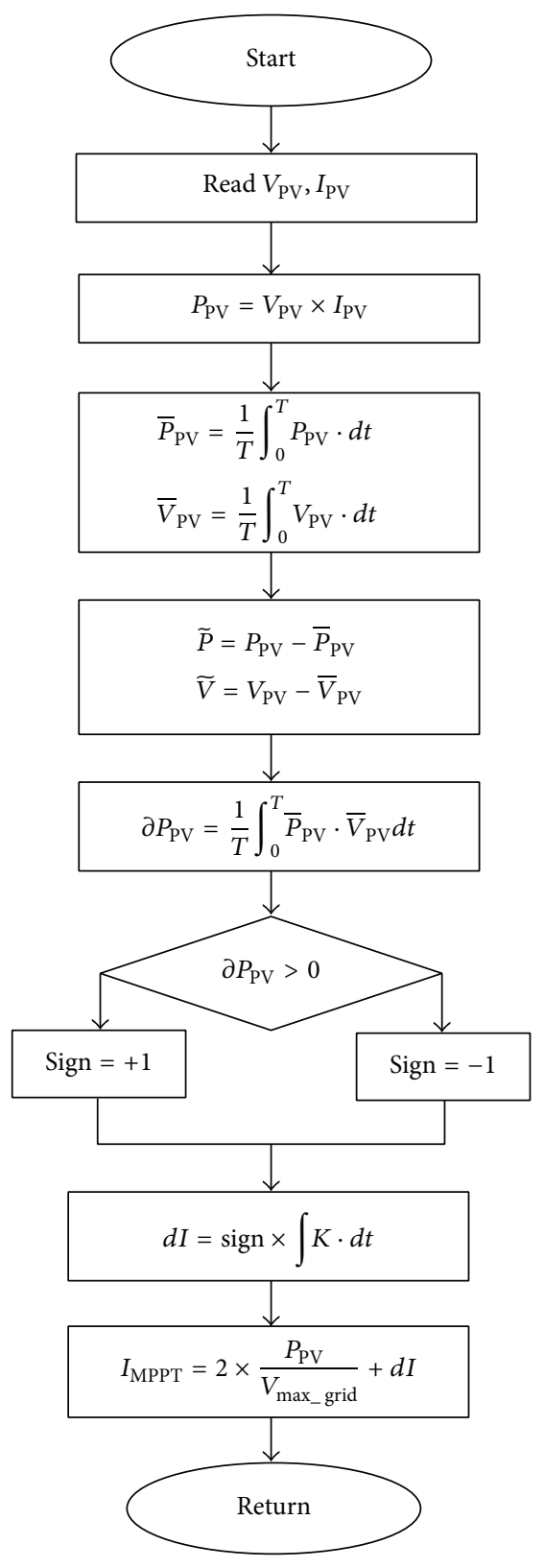

FIGURE 6: Flowchart of ripple correlation MPPT algorithm.

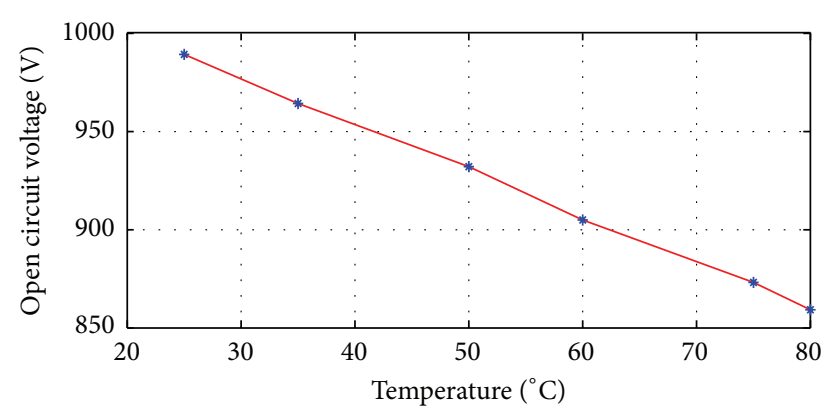

FIGURE 7: Variation of the open circuit voltage according to the temperature.

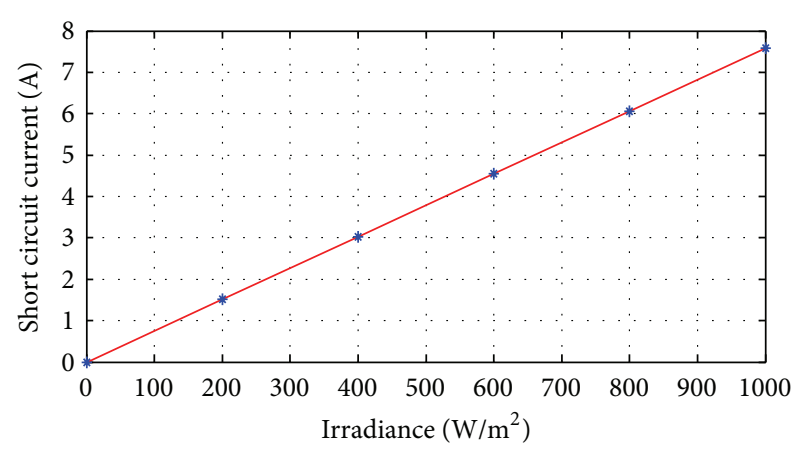

FIgURE 8: Variation of short circuit current according to the irradiation. 


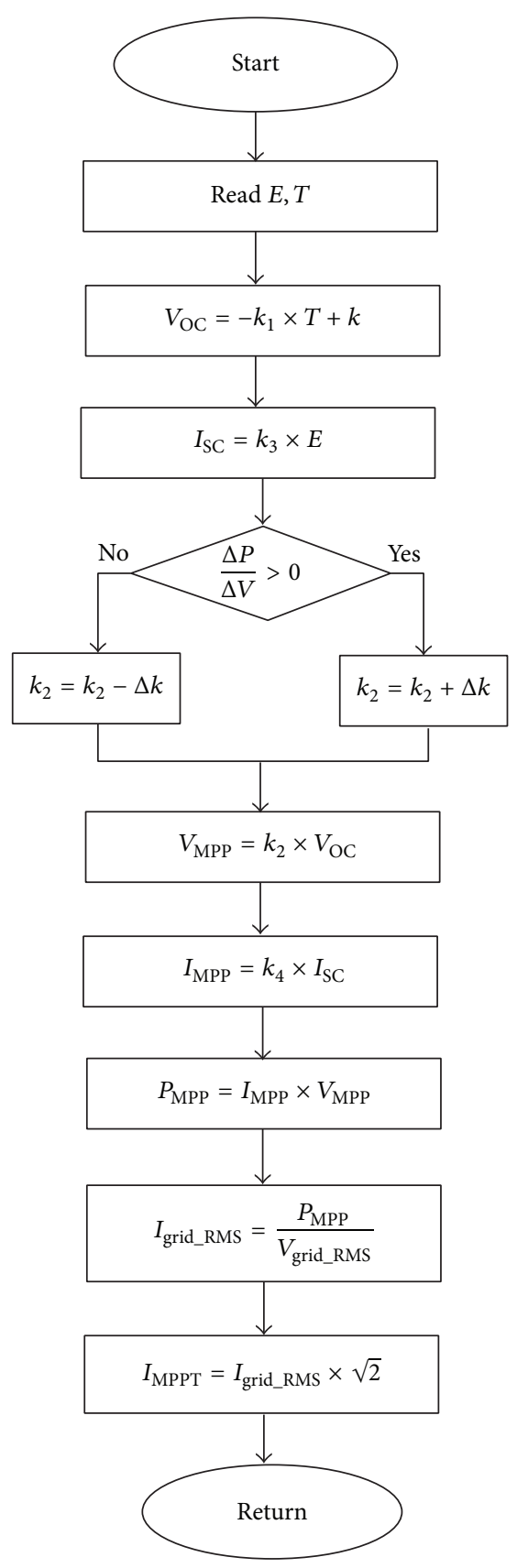

FIgURE 9: Flowchart of the proposed MPPT algorithm.

The proposed method needs using two sensors for the temperature and irradiation measurements.

This method needs also knowing the characteristics of the PV panels to determine the constant of the proposed algorithm in Figure 9.

For this purpose, a low-cost temperature sensor is adopted and is maintaining the right track of MPP but, in practical implementations, can be a problematic issue due to irregular distribution of PV array temperature, which can be avoided in small PV converters.

\section{Simulation Results}

In order to obtain a good characterization of the proposed topology, simulations were performed using PSIM software. The system was simulated under different operating conditions, in steady state and during transient state caused by solar radiation variations.

The $\mathrm{P} \& \mathrm{O}$ and IncCond techniques are the most widely used because of InCond and $\mathrm{P} \& \mathrm{O}$ simplicity to implement. But, as it can be seen in Table 1, their THD is high in 
TABLE 1: Efficiency of the different MPPT.

\begin{tabular}{|c|c|c|c|c|c|}
\hline \multirow{2}{*}{ MPPT } & \multirow{2}{*}{ Efficiency $(\eta \%)$} & \multicolumn{4}{|c|}{ THD (\%) } \\
\hline & & $1000 \mathrm{~W} / \mathrm{m}^{2}$ & $800 \mathrm{~W} / \mathrm{m}^{2}$ & $600 \mathrm{~W} / \mathrm{m}^{2}$ & $400 \mathrm{~W} / \mathrm{m}^{2}$ \\
\hline VSSOCV & 99.95 & 1.6 & 1.5 & 2.0 & 3.0 \\
\hline IncCond & 99.94 & 4.6 & 5.7 & 7.7 & 24.0 \\
\hline $\mathrm{P} \& \mathrm{O}$ & 99.93 & 1.7 & 1.9 & 7.1 & 9.0 \\
\hline $\mathrm{RC}$ & 99.86 & 2.1 & 3.8 & 2.0 & 8.0 \\
\hline
\end{tabular}

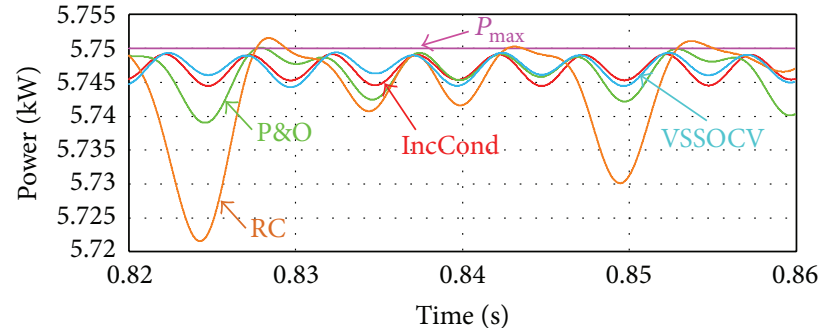

FIgURE 10: Power extracted from PV panels in steady state at $1000 \mathrm{~W} / \mathrm{m}^{2}$.

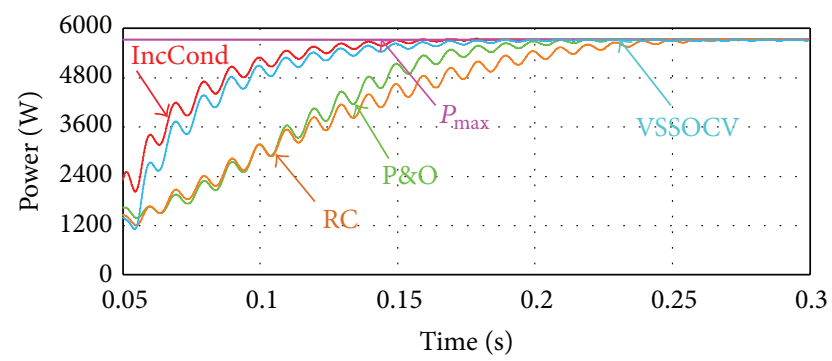

FIGURE 11: Power extracted from PV panels during the start-up with different MPPT techniques.

low radiation comparing with the proposed algorithm. Also, Figure 14 shows that it does not have a stable DC-link compared to the proposed MPPT and the ripple correlation method.

The proposed method is efficient and extracts the maximum power but it needs two sensors to measure the irradiation and temperature variation. This method needs only the knowledge of the $I-V$ characteristics. It has also the faster response.

IncCond has the highest rise time as it can be seen in Figure 11. We can see also, in steady state, that RC and $\mathrm{P} \& \mathrm{O}$ have the higher oscillation around the maximum point (Figure 10).

Table 1 shows also the efficiency of each method which is calculated using the maximum theoretical power and the instantaneous extracted power defined as

$$
\eta=\frac{P_{\text {actuel }}(t)}{P_{\max }(t)} \text {. }
$$

All the MPPT methods have an acceptable THD of the injected current which is less than $5 \%$ given in the interconnection standards (CEI61727) at $1000 \mathrm{~W} / \mathrm{m}^{2}$. Table 1 shows all

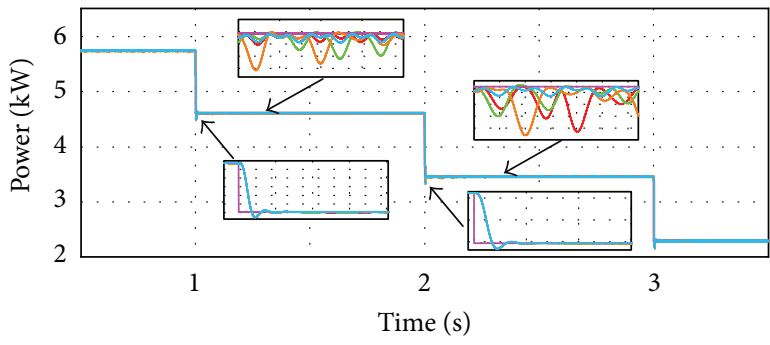

FIGURE 12: Maximum power extracted and theoretical power during a fluctuation in solar radiation from $1000 \mathrm{~W} / \mathrm{m}^{2}$ to $200 \mathrm{~W} / \mathrm{m}^{2}$ passing through $600 \mathrm{~W} / \mathrm{m}^{2}$ and $400 \mathrm{~W} / \mathrm{m}^{2}$.

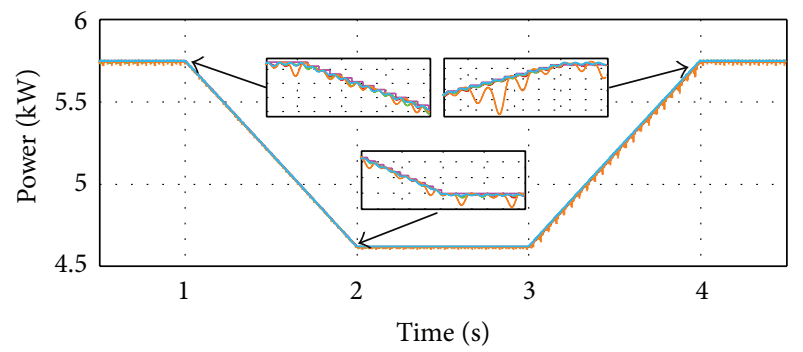

FIGURE 13: Maximum power extracted and theoretical power during a fluctuation in solar radiation from $1000 \mathrm{~W} / \mathrm{m}^{2}$ to $800 \mathrm{~W} / \mathrm{m}^{2}$.
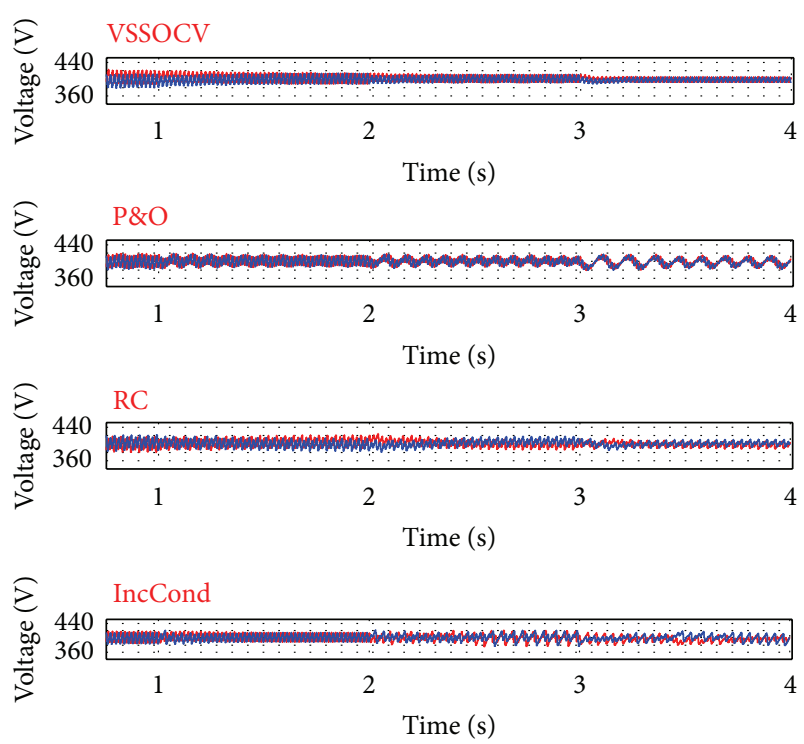

FIGURE 14: DC-link voltage with different MPPT. 

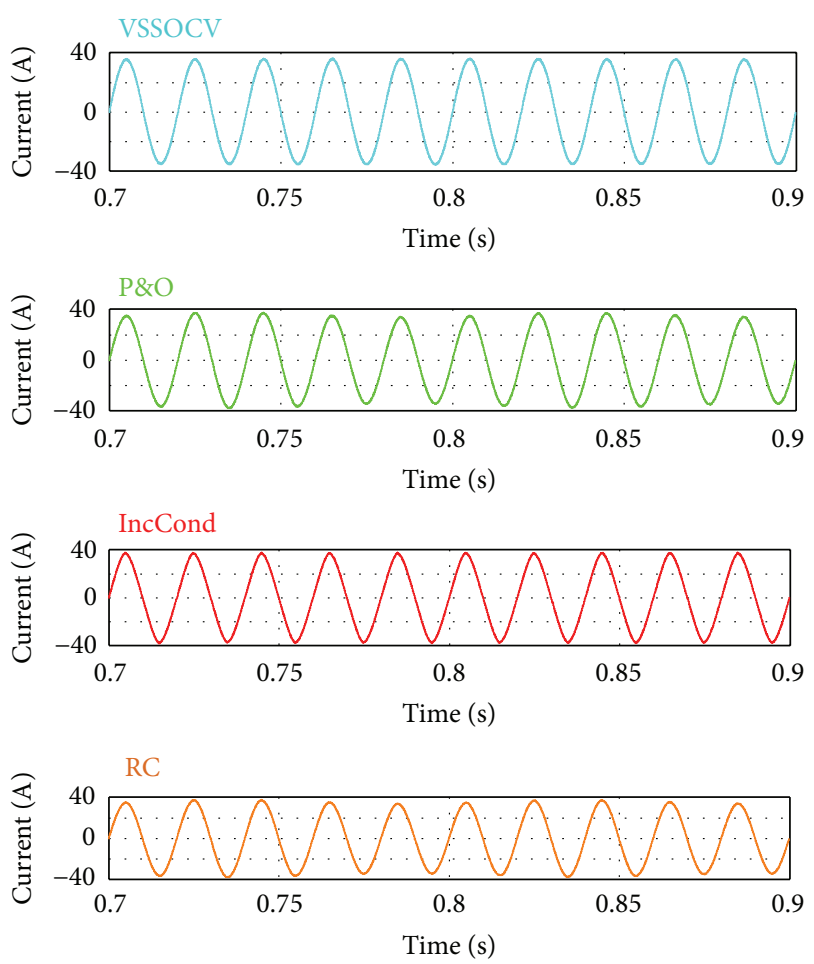

FIGURE 15: Injected current into the grid with different MPPT algorithms.

the THD of the different algorithms at different irradiation. It is clear that the proposed method VSSOCV has the best value of THD regardless of the irradiation.

The techniques are not equivalent concerning the costs and the software complexity but all of them require a microcontroller or DSP with higher performances due to the necessity of high computation capability.

The RC technique has an efficiency lower than the $\mathrm{P} \& \mathrm{O}$ and IncCond techniques, but its THD of the injected current to the grid is better than the $\mathrm{P} \& \mathrm{O}$ and IncCond.

Figures 12 and 13 show that all the techniques can extract the maximum power under different irradiation. Also, we can notice in Figure 15 that the currents injected into the grid are almost similar with the different MPPT.

The results show that the best MPPT technique is the proposed one (VSSOCV).

\section{Conclusions}

The purpose of MPPT is to extract the high level power from PV systems. This paper presents a comparison of MPPT methods with a proposed one which is the most effective on the basis of MPPT efficiency and considers their suitability for systems which experience a wide range of operating conditions. From this, it is clear that each MPPT method has its own advantages and disadvantages. In addition, the MPPT should be capable of minimizing the ripple around the MPP. Different MPPT methods are compared based on simulations in the PSIM environment in terms of the dynamic response of the PV system and efficiency and implementation

considerations. Therefore, the two techniques incremental conductance (IncCond) and $\mathrm{P} \& \mathrm{O}$ algorithms are simple to implement but they have some inconvenience in the DC-link and the output inverter current. Otherwise, the RC perturbs itself without an external perturbation. These three methods have been evaluated by simulating a grid connected PV system, utilizing a single phase NPC inverter to connect the $\mathrm{PV}$ panel to the grid. In particular, the performance of each method has been considered over a wide range of different irradiation conditions. It is shown that the proposed system is able to always extract the maximum power available from the solar PV panels with the proposed MPPT.

\section{Competing Interests}

The authors declare that they have no competing interests.

\section{References}

[1] A. Dolara, R. Faranda, and S. Leva, "Energy comparison of seven MPPT techniques for PV systems," Journal of Electromagnetic Analysis and Applications, vol. 1, no. 3, pp. 152-162, 2009.

[2] M. A. Elgendy, B. Zahawi, and D. J. Atkinson, "Assessment of perturb and observe MPPT algorithm implementation techniques for PV pumping applications," IEEE Transactions on Sustainable Energy, vol. 3, no. 1, pp. 21-33, 2012.

[3] H. Kumar and R. K. Tripathi, "Simulation of variable incremental conductance method with direct control method using boost converter," in Proceedings of the Students Conference on Engineering and Systems (SCES '12), pp. 1-5, Allahabad, India, March 2012.

[4] D. Casadei, G. Grandi, and C. Rossi, "Single-phase single-stage photovoltaic generation system based on a ripple correlation control maximum power point tracking," IEEE Transactions on Energy Conversion, vol. 21, no. 2, pp. 562-568, 2006.

[5] A. Reza Reisi, M. Hassan Moradi, and S. Jamasb, "Classification and comparison of maximum power point tracking techniques for photovoltaic system: a review," Renewable and Sustainable Energy Reviews, vol. 19, pp. 433-443, 2013.

[6] M. A. Elgendy, B. Zahawi, and D. J. Atkinson, "Assessment of perturb and observe MPPT algorithm implementation techniques for PV pumping applications," IEEE Transactions on Sustainable Energy, vol. 3, no. 1, pp. 21-33, 2012.

[7] H. Malek and Y. Chen, "BICO MPPT: a faster maximum power point tracker and its application for photovoltaic panels," International Journal of Photoenergy, vol. 2014, Article ID 586503, 9 pages, 2014.

[8] L. M. Elobaid, A. K. Abdelsalam, and E. E. Zakzouk, "Artificial neural network based maximum power point tracking technique for PV systems," in Proceedings of the 38th Annual Conference on IEEE Industrial Electronics Society (IECON '12), pp. 937-942, Montreal, Canada, October 2012.

[9] R. G. Tapre and R. G. Deshbhratar, "Comparative study and simulation of different maximum power point tracking (MPPT) techniques in a solar power generation," International Journal on Recent and Innovation Trends in Computing and Communication, vol. 3, pp. 143-148, 2015.

[10] K. Visweswara, "An investigation of incremental conductance based maximum power point tracking for photovoltaic system," Energy Procedia, vol. 54, pp. 11-20, 2014. 
[11] S. Z. Mirbagheri, S. Mekhilef, and S. M. Mirhassani, "MPPT with Inc. Cond method using conventional interleaved boost converter," Energy Procedia, vol. 42, pp. 24-32, 2013.

[12] T. Esram and P. L. Chapman, "Comparison of photovoltaic array maximum power point tracking techniques," IEEE Transactions on Energy Conversion, vol. 22, no. 2, pp. 439-449, 2007. 

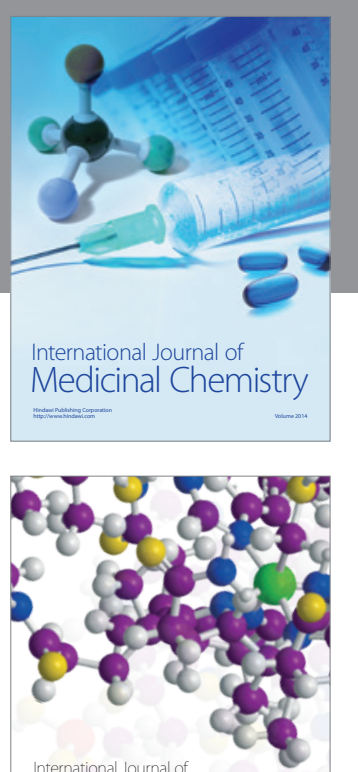

Carbohydrate Chemistry

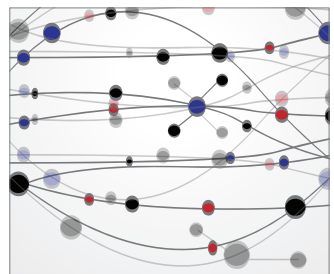

The Scientific World Journal
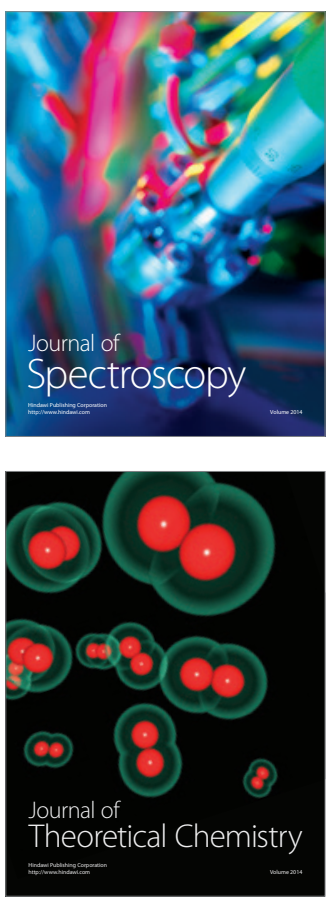
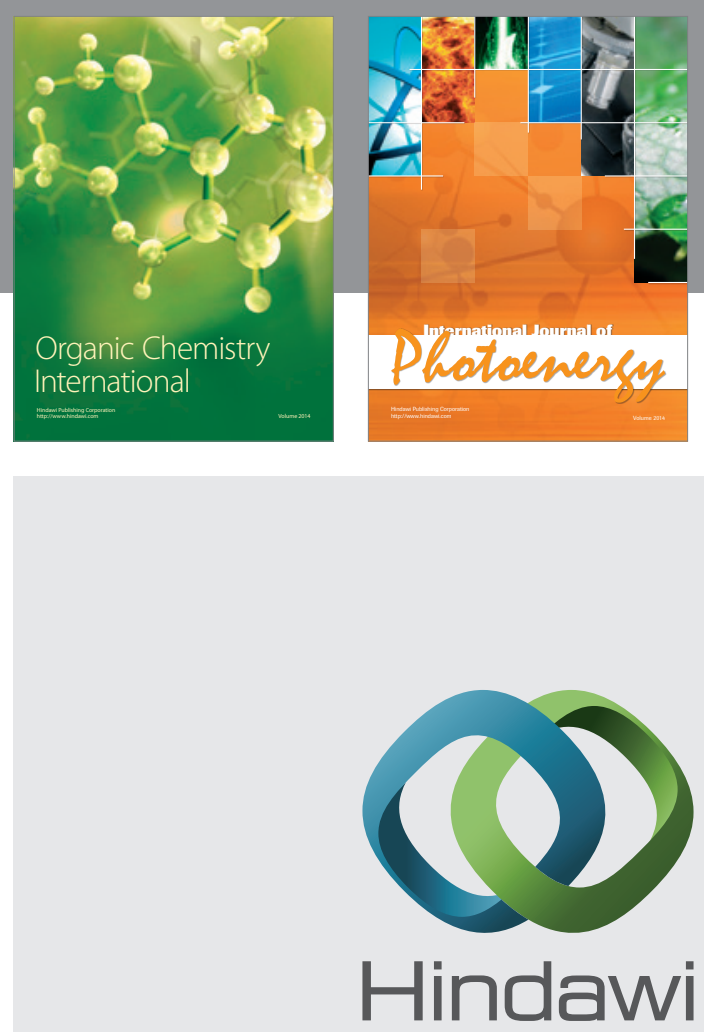

Submit your manuscripts at

http://www.hindawi.com

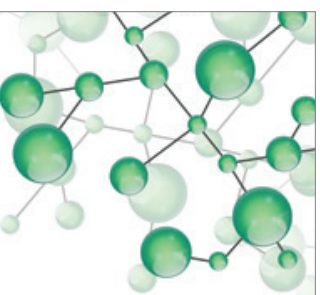

International Journal of

Inorganic Chemistry

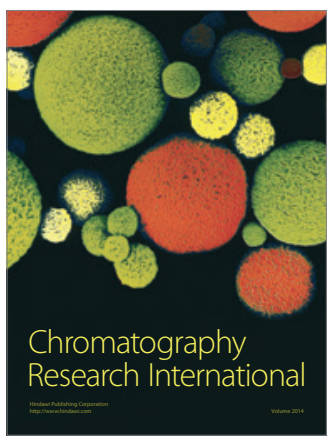

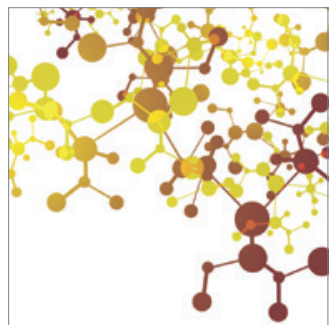

Applied Chemistry
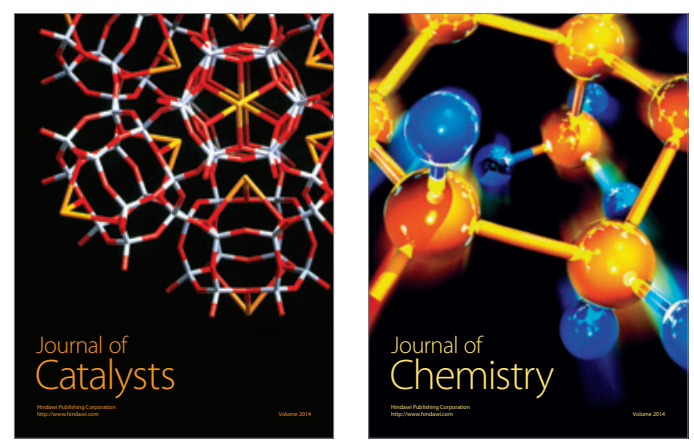
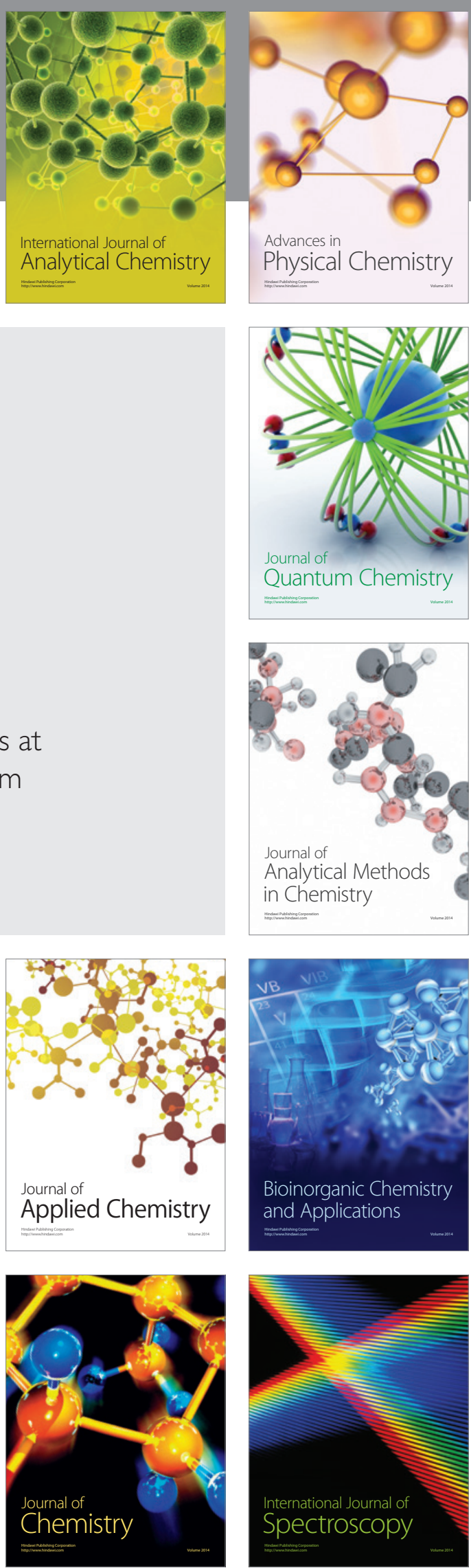